\title{
Dolor abdominal: no siempre es lo que parece
}

\author{
J. Morata Alba ${ }^{a}$, B. Pérez García ${ }^{b}$, P. J. Carpena Lucas ${ }^{c}$ \\ aServicio de Pediatría. Hospital Lluís Alcanyís. Xàtiva. Valencia. España • bediatra, Centro de Salud \\ Villanueva de Castellón. Departamento del Área de Salud Xàtiva. Valencia. España • 'MIR-Pediatría. \\ Servicio de Pediatría, Hospital Lluís Alcanyís. Xàtiva. Valencia. España.
}

2-septiembre-2015

Júlia Morata Alba: juliamorataalba@gmail.com

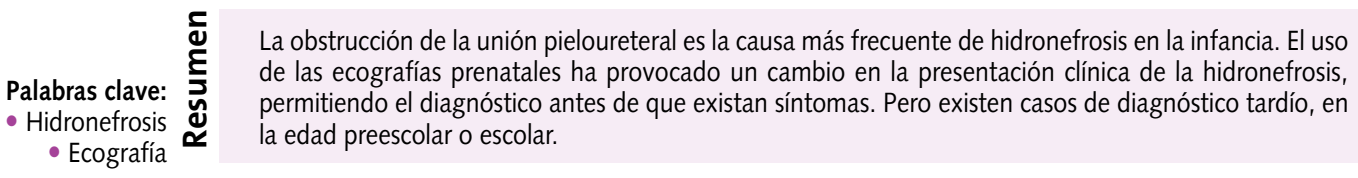

Abdominal pain is not always what it seems

\begin{abstract}
Ureteropelvic junction obstruction is the most common cause of pediatric hydronephrosis. The typical presentation of hydronephrosis has changed since the widespread use of antenatal ultrasonography and nowadays diagnosis may be set before symptoms begin. But there are cases of late diagnosis in preschool or school age.
\end{abstract}

\section{INTRODUCCIÓN}

La obstrucción de la unión pieloureteral (UPU) es la causa más frecuente de hidronefrosis en la infancia. Se produce como consecuencia de la estenosis de la unión entre la pelvis renal y el uréter. La obstrucción de la UPU origina restricción al flujo urinario desde la pelvis a la porción proximal del uréter y, como consecuencia, se produce un incremento retrógrado de la presión en la pelvis renal. Este incremento de presión provoca daño parenquimatoso, pudiendo llegar a la anulación funcional del riñón. La forma de presentación de la hidronefrosis en la edad infantil ha variado en los últimos años. La instauración de las ecografías prenatales en el control rutinario del embarazo permite en la actualidad realizar el diagnóstico antes de que se inicien los sintomas ${ }^{1-3}$.

El diagnóstico de estenosis de la unión pieloureteral se realiza por ecografía renal y renograma isotópico. La ecografía diagnostica el grado de dilatación y el estado del parénquima renal y el renograma isotópico determina la existencia de obstrucción en la vía urinaria.

La dilatación del sistema urinario superior es la anomalía fetal más frecuente, llegando a afectar a uno de cada 100 gestantes. Solo una de cada 500 de estas dilataciones tendrá repercusión clínica. La 
incidencia de estenosis de la UPU es de uno de cada 1500 recién nacidos vivos. Es más común en varones (3-4/1) y afecta con mayor frecuencia (60\%) al riñón izquierdo. En un 20-40\% de los casos es bilateral.

Un pequeño porcentaje de casos con estenosis congénita de la unión pieloureteral pasan desapercibidos en las ecografías prenatales y son diagnosticados tardíamente, pudiendo conllevar este retraso de diagnóstico un daño importante del parénquima renal, que en ocasiones es irreversible ${ }^{4}$.

En estos casos, los síntomas son dolor abdominal, que puede ir acompañado de vómitos, infección urinaria, hematuria macroscópica espontánea o tras un traumatismo banal. Otros síntomas son masa abdominal o el dolor abdominal difuso.

En los casos de diagnóstico en la infancia tardía se debe estudiar el parénquima renal y la función renal.

\section{CASO CLÍNICO}

Niño de ocho años con molestias abdominales intermitentes difusas en los últimos años, atribuidas a procesos banales agudos. Sin antecedentes personales ni familiares de interés. Sin infecciones de orina ni otra sintomatología urinaria.

Coincidiendo con un episodio de dolor abdominal en hemiabdomen derecho, se realizó una ecografía abdominal, en la que se objetivó una adenitis mesentérica y una dilatación de pelvis renal derecha leve (Fig. 1), con sospecha de estenosis de la UPU. Sedimento de orina y urinocultivo normales.

Desapareció la clínica de dolor abdominal espontáneamente, pero se remitió a Nefrología Pediátrica para control evolutivo.

En la ecografía de control, estando asintomático, se seguía visualizando la dilatación de la vía urinaria con dilatación de pelvis renal derecha grado leve-moderada, por lo que se solicitó renograma isotópico (sospecha de estenosis de la unión pieloureteral). El renograma (Fig. 2) confirmó una ectasia obstructiva en riñón derecho. En el estudio de gammagrafía renal se objetivó aumento del tamaño renal derecho, con evidente hipocaptación

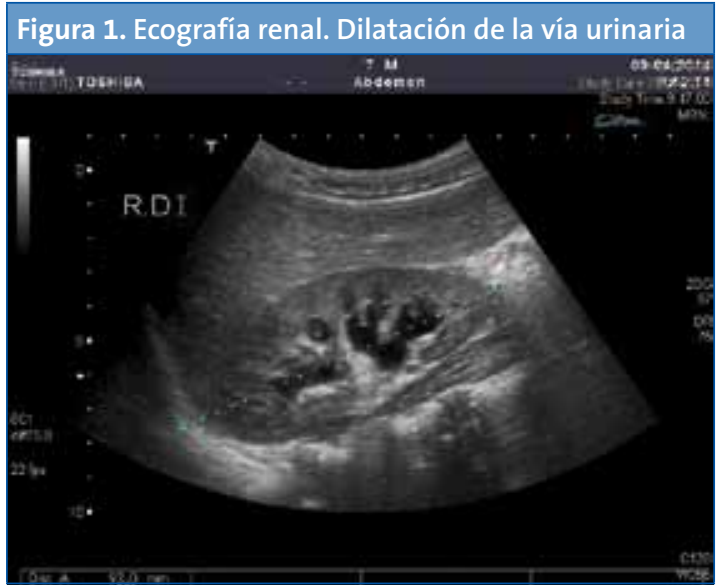

en todo el borde medial, signos de dilatación de vía, con una función renal del $58,8 \%$ en riñón izquierdo y del $41,2 \%$ en riñón derecho.

Ante la dilatación del tracto urinario de causa obstructiva se remitió a Urología Infantil para intervención quirúrgica. Se colocó un catéter de nefrostomía durante unos meses para recuperar y evitar el deterioro de la función renal ${ }^{5,6}$. Tras la retirada del catéter de nefrostomía se siguieron realizando controles de imagen, clínicos y analíticos, normalizándose progresivamente.

\section{DISCUSIÓN}

La obstrucción de la unión pieloureteral constituye una causa predominante de la hidronefrosis obstructiva en Pediatría. La realización de ecografías prenatales en cada trimestre del embarazo ha supuesto un incremento en el diagnóstico de las dilataciones de la vía urinaria en el periodo neonatal, permitiendo realizar un adecuado seguimiento y tratamiento con el fin de disminuir el daño renal.

Algunos casos son diagnosticados tardíamente, en la edad preescolar o escolar. Estos casos deben ser diagnosticados lo más precozmente posible y ser estudiados correctamente, dado que en ocasiones requieren cirugía. El interés del diagnóstico y/o tratamiento es conseguir minimizar el daño renal, así como una recuperación de la función renal tras la cirugía ${ }^{5,6}$ 


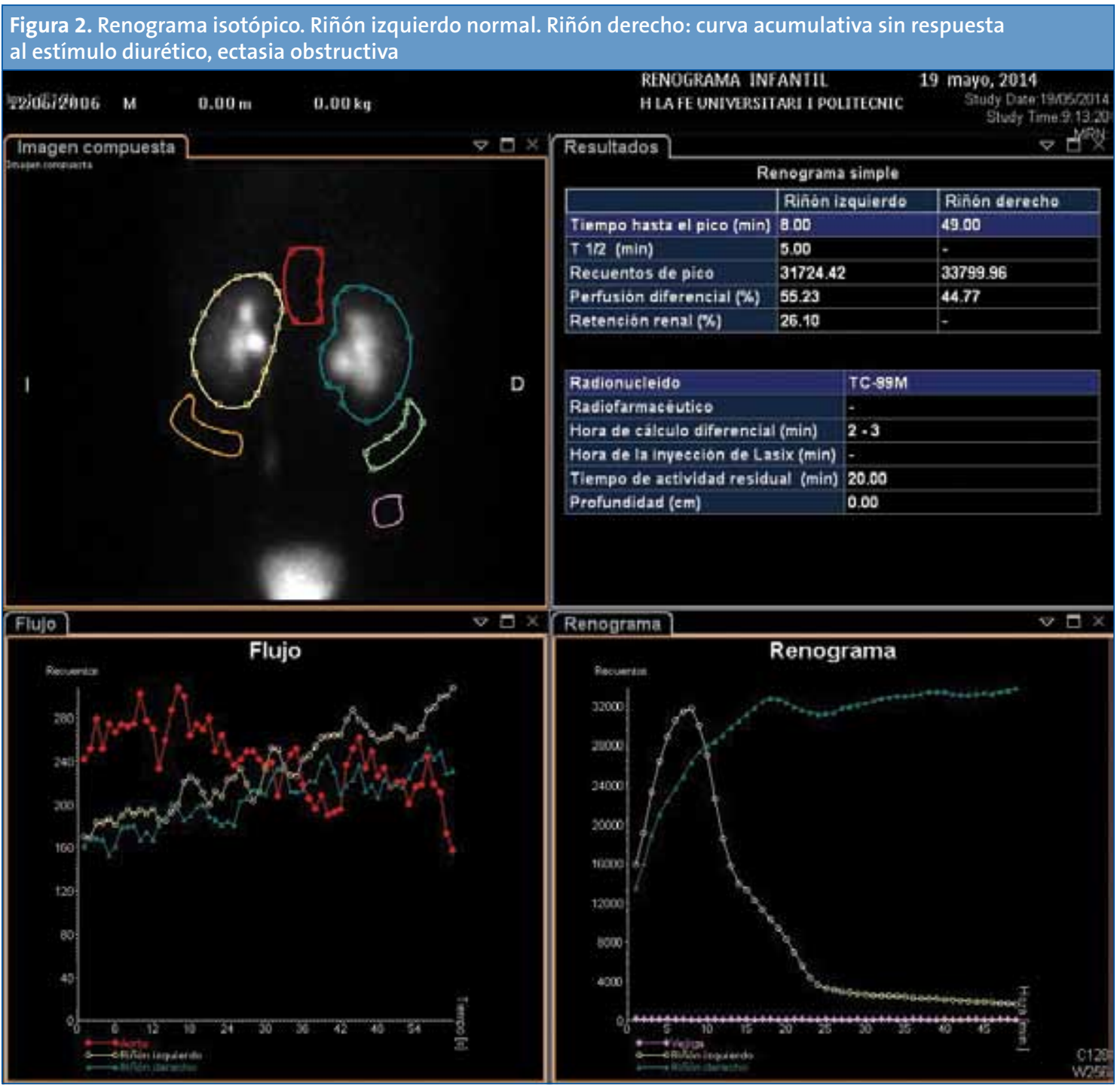

Existen casos de estenosis de la unión pieloureteral de presentación tardía y secundarios a compresiones extrínsecas de la vía urinaria que tienen, por lo general, un buen pronóstico, con menor daño parenquimatoso renal y mayor recuperación tras la desobstrucción. El dolor abdominal puede ser un síntoma guía.

\section{CONCLUSIONES}

La ecografía prenatal es una herramienta de diagnóstico útil para detectar uropatía, especialmente la estenosis de la unión pieloureteral. Es importante remarcar, dado el daño renal secundario posible, que se deben realizar más estudios complementarios cuando en ecografía posnatal existe una dilatación de la vía urinaria igual o superior a $16 \mathrm{~mm}$ o grado 4, según la Society for Fetal Urology.

\section{CONFLICTO DE INTERESES}

Los autores declaran no presentar conflictos de intereses en relación con la preparación y publicación de este artículo.

\section{ABREVIATURAS}

UPU: unión pieloureteral. 


\section{BIBLIOGRAFÍA}

1. Rianthavorn P, Limwattana S. Diagnostic accuracy of neonatal kidney ultrasound in children having antenatal hydronephrosis without ureter and bladder abnormalities. World J Urol. 2015 [en prensa].

2. Nickavar A, Nasiri SJ, Lahouti Harahdashti A. Changing trends in characteristics of infantile hydronephrosis. Med J Islam Repub Iran. 2014;7:40.

3. Ylinen E, Ala-Houhala M, Wikstrom S. Outcome of patients with antenatally detected pelviureteric junction obstruction. Pediatr Nephrol. 2004;19:880-7.
4. Papachristou F, Pavlaki A, Printza N. Urinary and serum biomarkers in ureteropelvic junction obstruction: a systematic review. Biomarkers. 2014;19:531-40.

5. Hensle TW, Shabsigh A. Pyeloplasty (Anderson-Hynes). BJU Int. 2004;93:1123-34.

6. Gupta DK, Chandrasekharam VV, Srinivas, Bajpai M. Percutaneous nephrostomy in children with ureteropelvic junction obstruction and poor renal function. Urology. 2001;57:547-50. 